\title{
Methods to Provide Supply and Demand Balance on the Regional Industrial Labour Market (By Qualifications)
}

\begin{abstract}
G.R. Mukhametshina
A.N. Bulatov

N.V.Antonova

Doi:10.5901/mjss.2014.v5n12p145

abc Kazan Federal University, Kazan, 420008, Russia

Abstract

This article deals with the problem of professional and qualification balance on the regional labor market and the ways to resolve them. It is shown that the Republic of Tatarstan labor market is characterized by lack of balance; it abounds in highly qualified professionals especially in humanities, and lacks qualified workers. The author develops a method, which can provide supply and demand balance on the industrial labor market of the region. He also shows different interaction patterns between regional authorities on the one part, and factories and educational institutions on the other part, in order to provide this balance.
\end{abstract}

Keywords: labor market, professional qualification structure, higher education, balance, employment

\section{Introduction}

The effectiveness of regional economic progress depends to a large extent on balance on the labor market. This balance in its turn is a prerequisite to providing long term stable increase in national welfare [8].

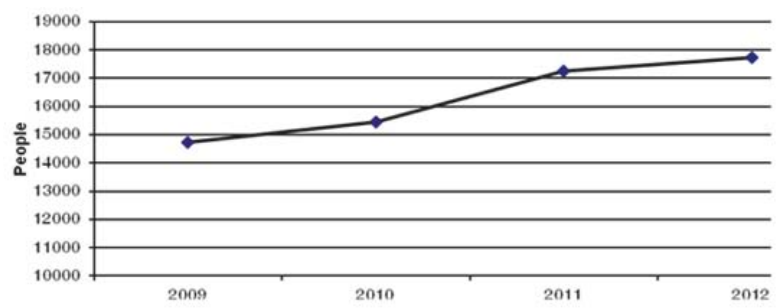

Fig.1. Trends in higher professional institutions graduation rates (the department of Economics and Management) in the Republic of Tatarstan.

Yet, as you can see in fig.1, there is a dramatic increase in training higher qualified workforce especially in economics, management and law. It is estimated that about $40 \%$ of such students cannot find work that corresponds to their qualification level. At the same time, the republic of Tatarstan economy lacks qualified workers.

\section{Theory}

Literature on this subject has no agreement of opinions on the mechanisms to provide balance on the occupational labor market. P. Bir and T. Skills stick to liberal approach to this problem [3].

A. Daunts highlights the fact that active interference of the government into the above-named processes can only be justified for low competitive developing labor markets [4]. J. Li cites the positive experience of Taiwan, where the state created conditions to form a system of highly technological education which responded to the needs of innovative development of their economy [7].

V.V. Druzhinina emphasizes the need for priority principle in securing equilibrium while developing regional and local occupational labor markets. She asserts that this balance has an immediate effect on the level of working efficiency [5]. 
J.A. Seitkhozhina admits the importance of equilibrium in developing labor market, though she pays special attention to balance in gender, and especially age, but not professional qualifications [11]. We cannot fully agree with this approach. Forming demand for remote or half-time employment of particular professional groups we can give an opportunity to get employment for citizens under working-age or retirees. Therefore, gender disproportion in labor market development smoothes itself.

In the RT (Republic of Tatarstan) economics labor market equilibrium is considered one of the key factors, which provides progressive development of the regional economy as a whole [1], [6], [9]. It is shown that such balance must be supported by the principle of work flows dynamism in the general economic development system of the region [10].

We should note that the RT (Republic of Tatarstan) Ministry of Labor and Employment, the RT Federal state statistics service and the RT Economic society carried out a work on monitoring occupational employment but no specific methodical decisions, such as regional laws, were taken.

\section{Results}

We offer a set of methods which can provide balance on the regional occupational labor market. It includes the following basic steps:

1. To conduct population employment monitoring by education and professional qualifications in different types of business in the regional industry. This must be a promiscuous monitoring which embraces all large-scale, medium-size and the majority of small industrial enterprises. As a result of the monitoring and the subsequent procession of its results the following data must be obtained for each sphere of business (which is in fact a brunch of industry)

- Number of employees in each profession by their education (higher, secondary or primary) for each type of business, and fraction of the profession members in the total industrial employment structure (no less than 8-9 reporting periods);

- Staff redundancy rate for the same business types and professional groups during the same period. This must be a ratio of employees dismissed by any reason to average number of staff members in the respective professional field.

The government of the Republic of Tatarstan can develop an appropriate questionnaire and obligate all the personnel departments of manufacturing enterprises to carry out such a monitoring. It may be rather difficult for the personnel department managers to reproduce the number of personnel in each professional field during the last 8-9 years (which is the least range of observations necessary to create a representative statistical model). However with the aid of automatic equipment for recording personnel status and staff turnover this task can become feasible.

2. To carry out a social research in order to find out the number of students of each study field, graduating from institutions of primary professional education, secondary professional education and tertiary professional education, who leave the region shortly after completing their studies, within a year, for example. It is difficult to obtain such information about all graduating students therefore a sampling study is more appropriate. With the help of the same method of surveying we must estimate the number of graduating students from other regions who arrive in the region under investigation (for example, the Republic of Tatarstan) to get permanent employment.

3. To create statistical functions which show how the main parameters of development of a certain business sphere influence the demand for personnel of particular professional groups (for each profession and activity). (1)

ППі = f (ОПј, ИТј, ЭУј) (1)

where $\Pi \Pi \mathrm{i}-$ is the demand for professionals of a certain qualification group at $\mathrm{j}$-type manufacturing enterprises in the regional industry;

$\mathrm{O} \mathrm{\Pi j}$ - is the speed of change in real production bulk for the particular type of business during the corresponding period (the 8-9 years mentioned above)

ИTj - is the rate of changes in investments to labor-saving technologies by manufacturing enterprises of a certain type in the regional industry;

$\ni \mathrm{Yj}$ - is average business management efficiency for this type of business in the region (the rate is estimated by means of an expertise for each of the previous periods, using a unified scale, such as $0-10$ ).

It is quite evident that demand for certain professions is directly related to changes in real production for certain types of business in the regional industry. Yet if we reduce for example the output, the rate of dismissal of professionals in different spheres may differentiate substantially. To identify such rates we need statistical analysis. 
Moreover, the change in total number of professionals in a particular sphere is supposed to depend on the intensity of investments to labor-saving technologies by the corresponding manufacturing enterprises. In general, adoption of labor-saving technologies is a relevant objective in business innovation programmes. Such technologies include expenditures on innovative high-performance equipment, which minimize the amount of "living labor", adopting innovative automatic industrial control systems and technologies, including ERP -systems, etc.

Expansion of labour-saving technologies will cause the following changes in the employment structure of certain business types in the regional industry: demand for workers, especially unqualified, will go down; demand for skilful workers able to handle innovative equipment will rise; demand for engineering personnel will slightly increase; and demand for management personnel will slightly decrease. It should be noted that the rate of change of such demand may vary for different business types in the industry of the region.

Finally, we should evaluate, at least with the help of an expert study, average efficiency of management at manufacturing enterprises of this type. The fact is that demand for personnel partly depends on quality of management the lower the level of the latter, the more probable is unreasonable employment of excessive number of professionals in different spheres (basically management personnel), stagnation of personnel, limited employment of interns, and other negative facts. To carry out such an expert study at manufacturing enterprises of a certain type in the regional industry we can invite specialists from the regional Ministry of Economy, trade Universities, etc.

4. To forecast the rate of change in production volume, investments in labor -saving technologies, and management efficiency for each business type in the regional industry. For such a forecast we can use a synthesis of statistical extrapolation methods, plans and programmes approved by the regional Ministries and departments, as well as expert evaluations.

5. To predict the number of specialists in each profession for each business type based on functions type (1) and predict factor variables for the corresponding business types (methodology, point 4) in the following 7-8 years.

6. To evaluate possible future demand for specialists of different education and qualifications levels by summing up the expected values for each business type.

7. To evaluate the demand for preparing specialists in the respective professional fields (2)

ППС $=$ ПП(sum)i * $(1-\mathrm{ki})+\mathrm{Mi}(2)$

where ППС - is the demand for students (secondary and primary professional education) of 'i' professional group to be admitted by educational institutions of the region in the current academic year;

$\Pi \Pi($ sum) I - is the total demand for personnel in certain professional field (methodology point 6) after the corresponding period of tuition (usually 5 years for higher professional institutions, and 3 years for specialized secondary education and primary professional education); point 1);

$\mathrm{ki}$ - is the average staff redundancy rate for this professional field identified by means of monitoring (methodology,

$\mathrm{Mi}$ - is the migration balance of graduates. It is a difference between students leaving the region and those arriving in it immediately after graduating from corresponding educational institutions.

8. To inform the general public of the region (school-leavers and their parents in the first place), enterprises, and professional education institutions of the results of the research into demand for preparing different types of professionals in the region.

9. To choose a strategy to interact with enterprises and professional education institutions based on the results of the previous estimates of demand for qualifications (table 1).

Table 1: Possible strategies for interaction between the regional authorities and professional education institutions and enterprises of the region in order to balance demand and offer on the occupational labor market

\begin{tabular}{|c|c|c|}
\hline Strategy & Advantages of the strategy & Disadvantages of the strategy \\
\hline $\begin{array}{l}\text { 1. Passive strategy implies problem evasion. Hence the } \\
\text { problem of professional imbalance on the regional labor } \\
\text { market remains unsolved. }\end{array}$ & Minimal expenditures & Aggravation of the problem \\
\hline $\begin{array}{l}\text { 2. Informing strategy aims to limit activities in this sphere, i.e. } \\
\text { informing all the interested parties on the results of the } \\
\text { education demand monitoring. }\end{array}$ & $\begin{array}{l}\text { Comparatively low cost (organization and } \\
\text { monitoring only). Increase in information } \\
\text { awareness among school-leavers and their } \\
\text { parents. }\end{array}$ & $\begin{array}{l}\text { Lack of efficient interaction with education } \\
\text { institutions of the region on the subject of } \\
\text { the problem resolution. }\end{array}$ \\
\hline $\begin{array}{l}\text { 3. Active strategy which implies influencing key figures of } \\
\text { university intake in accordance with the expected demand for } \\
\text { graduates from particular programmes. }\end{array}$ & $\begin{array}{c}\text { Provides high balance between university } \\
\text { admission and demand on the regional labor } \\
\text { market. }\end{array}$ & $\begin{array}{l}\text { Difficulty in immediate influence on } \\
\text { number of students at universities } \\
\text { especially non-governmental ones. }\end{array}$ \\
\hline $\begin{array}{l}\text { 4. Active strategy which implies interaction with the regional } \\
\text { manufacturing enterprises in order to encourage them to } \\
\text { organize in-house training for their prospective employees. }\end{array}$ & $\begin{array}{c}\text { Encourages businesses to prepare appropriately } \\
\text { trained staff. }\end{array}$ & $\begin{array}{c}\text { Not all manufacturing enterprises possess } \\
\text { enough funds to realize their own } \\
\text { educational programmes. }\end{array}$ \\
\hline
\end{tabular}


So, the most appropriate alternative is a synthesis between the third and the fourth strategies represented in table 1 (interaction strategies between regional authorities and economic entities regarding long-term demand-supply balance on the regional occupational market). At the same time it is important that regional enterprises, especially large ones, created educational programmes for in-house learning to train specialists, to be demanded in future. (Fig.2).

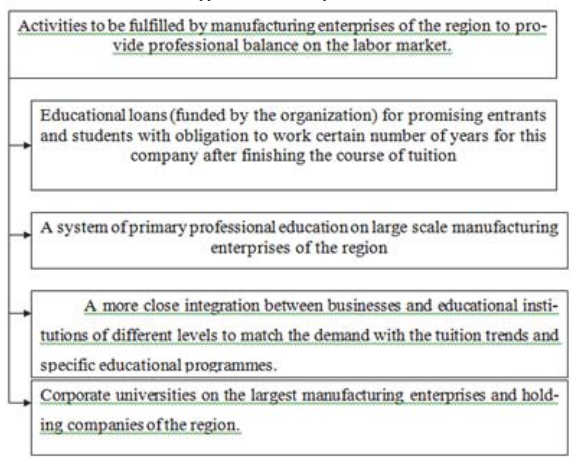

Fig. 2. Possible vectors for manufacturing enterprises of the region to provide professional balance on the labor market.

The state can assist the arrangements providing long-term stable balanced development of the regional labor-market shown in fig.2, by means of organization support, tax remissions for the businesses creating self funded institutions of primary professional education and corporate universities, etc.

\section{Conclusions}

The problem of permanent mismatch between supply and demand on the labor market in the Russian Federation and some of its regions requires an integrated solution, strongly supported by the regional authorities. The proposed method can help predict need for people with specific training qualifications taking into account the pace of development of certain business types in the regional industry. At the same time with initial representative information such a forecast can be made for professional fields of wide coverage: from key qualifications to field-specific qualifications.

The optimal state policy does not only consist in passive informing all the interested parties on the prospective demand for personnel, but active cooperation with the institutions in verifying the check figures of admission for different educational programmes, as well as close contact with manufacturing enterprises of the region.

\section{References}

Bagautdinova, N.G., Gafurov, I.R., Novenkova, A.Z. The transformation of region's economic area governed by the development of industrial region // World Applied Sciences Journal , 2013, №25 (7) p.p.. 1113 - 1117

Safiullin, M.R., Eflova, M.Yu., Nagimova, A.M. Social moods and self-identification of middle class in Tatarstan // Sotsiologicheskie Issledovaniya, 2012, №10, pp. 28 - 33

Bagautdinova, N.G., Panasyuk, M.V., Gafurov, I.R. Wavelet analysis of the territorial socio-economic system dynamics // World Applied Sciences Journal ,2013, №27 (13), p.p.. 62 - 66

Beer P., Schils T. The labour market triangle - Wash.: Edward Elgar Pub, 2010. - 238 p.

Downes A. Labour markets in small developing states. - NY,2008. - $146 \mathrm{p}$.

Druzhynina V.V. Formation principles for the mechanism of the local labour market balancing // Актуальні проблеми економіки, № 4 (142), 2013, pp. $202-208$.

Kirshin, I.A., Datsyk, A.A., Titov, A.V. Forecasting the dynamics of an innovative cycle // World Applied Sciences Journal, 2013, №27 (13) , pp. $197-201$

Lee J. The labour market and economic development of Taiwan. - Wash.: Edward Elgar Pub, 2007. - 329 p.

Fakhrutdinova E.V., Kolesnikova J.S., Suleimanov T.D., Khalikov A.L. The interrelation of the problems of the youth labour market and the "brain drain". Life Science Journal 2014; 11(6s): 473 - 477.

Seitkhozhina J.A. Gender asymmetry at the labour market in the republic of Kazakhstan // Актуальні проблеми економіки, № 1 (151), 2014, pp. $368-375$.

Safiullin, M.R., Elshin, L.A., Prygunova, M.I., Galyavov, A.A. Complex analysis of prospects of the Volga Federal District regions development: Methodology and practice // World Applied Sciences Journal, 2013, №27 (4), pp. 508 - 511 